\title{
Tecnopolíticas de Gênero
}

As relações entre tecnologias, gênero $e$ ativismos contemporâneos constituem o tema central que guiou a organização do dossiê Tecnopolíticas de Gênero. Os artigos propõem desdobrar as associações entre técnicas, artefatos, tecnologias, informação, corpos e gênero. Inspiradas por uma noção aberta de técnica e de tecnologia, que incorpora e expande sua acepção restrita às tecnologias de informação e comunicação (TICs), propomos discussões que levam em conta as ações técnicas $e$ agenciamentos de corpos, linguagens, coisas e artefatos em conexão com as diversas redes que os constituem, $e$ as questões de gênero que emergem com esses processos.

Interessa-nos pensar e explicitar esses processos em sua dimensão tecnopolítica, seguindo a intuição de Donna Haraway (1991) ao propor o ciborgue como um mito-ficção política possível para um feminismo "de esquerda" no contexto da "informática da dominação". Nesse sentido, importam as formas como máquinas e organismos se articulam na constituição das redes de poder, informação e comunicação.

Como já previa Haraway na década de 1980, ao mapear a "virada cibernética", organismos e máquinas passaram a ser pensados a partir do paradigma das ciências da informação. Moléculas, células, genes, memórias, fluxos de energia, de dados, de códigos, vírus, avatares, perfis são entes materiais-semióticos que ocupam nossos corpos, compõem nossas existências $e$ organizam nossa relação com o mundo. Não há como separar nossa imaginação e sua expressão em texto, imagem, caracteres, bits, pixels, perfis, visualizações, viralizações. Somos corpos e máquinas.

Entender como poder e técnica se constituem em corpos e computadores já era, no final do século $\mathrm{XX}$, e segue sendo ainda hoje, uma tarefa imprescindível para o feminismo e para produzir 
resistências e transformações diante das desigualdades produzidas pelo capitalismo. Reconhecer-se ciborgue não tem nada a ver com tecnofilia acrítica, nem tampouco com uma tecnofobia paralisante. Está em algum lugar entre essas duas posições.

Como, então, "herdar" (Despret e Stengers, 2011) as tecnociências ocidentais, que produziram as máquinas comunicantes que hoje performamos em nossos múltiplos agenciamentos, mas desfazendo-nos das suas práticas de violência $e$ de exclusão? Como ocupar as redes, colonizadas pelo capitalismo e pelo patriarcado (misógino, racista, homo/trans/bifóbico e capacitista) e transformar, subverter, curar as dinâmicas de dominação e de morte que se reproduzem através delas? Nesses desafios se constituem os contextos sociotécnicos mapeados nos trabalhos que se seguem.

$\mathrm{O}$ arranjo dos textos propõe três eixos consecutivos de discussão, que traçam um diálogo sobre: o campo das infraestruturas tecnológicas e das redes autônomas e comunitárias; as tensões de visões limitantes e excludentes sobre gênero $e$ tecnologia, e os ativismos no campo das TICs; e sobre como as relações entre corpo, gênero e saúde aparecem mobilizadas em temáticas ligadas às TICs, aplicativos, redes sociais e às tecnologias de transformação corporal.

No primeiro conjunto de textos, os trabalhos colocam no centro da discussão embates e temáticas específicas, como autonomia, privacidade, anonimato, segurança digital e violência de gênero, procurando apresentar formas contemporâneas de articulação política, e de resistência, a partir das experiências de ativistas.

Sophie Toupin e Alexandra Hachè exploram a criação e conceitualização das "infraestruturas autônomas feministas", que advêm de experiências diversas em redes e coletivos de hackerativismo feminista. Ecoando um tom de manifesto, as autoras apontam para $e$ identificam-se com as necessidades $e$ a importância de uma apropriação feminista das tecnologias de informação e comunicação e suas infraestruturas. O texto mobiliza a importância de fortalecer alianças entre a produção acadêmica $e$ 
a potência política de temas e práticas como as ciber/hack/tecnofeministas.

Em diálogo com esse debate mais amplo sobre infraestruturas autônomas, o artigo de Daniela Araújo, Débora Oliveira e Marta Kanashiro apresenta um quadro nascente de discussão sobre Tecnologia Feminista. Tem como ponto de partida as experiências de coletivos de mulheres, e projetos desenvolvidos na América Latina, na interface com conhecimentos sobre internet, autonomia, infraestruturas digitais e segurança da informação. O texto procura discutir as implicações para a construção de redes sociotécnicas quando elas almejam romper o legado colonial $e$ androcêntrico. Os sentidos $e$ articulações que emergem das construções tecnopolíticas em torno do conceito de "Tecnologia Feminista" revelam o empenho e interesse dos coletivos em incorporar perspectivas múltiplas, que resgatem a memória $e$ os saberes locais $e$ questionem universalizações $e$ hierarquizações do conhecimento e suas técnicas.

As redes comunitárias e os modelos de conectividade são especialmente tratados por Nicola Bidwell a partir do entrelaçamento entre tecnologia, gênero, gerações e práticas comunitárias localizadas. $\mathrm{O}$ artigo analisa esses aspectos com base na experiência de campo da autora em redes locais e rurais na África, América Latina e Sul da Ásia. Bidwell analisa a possibilidade de correlacionar esses dados $e$ os discursos $e$ políticas globais de telecomunicações e tecnologias, delineando as diferentes camadas de relações de poder embutidas nas infraestruturas das TICs, que têm a ver com gênero, tecnologia, geração e ruralidades.

As experiências de ativismo digital mapeadas por esses trabalhos mostram que é preciso localizar as formas de incidência e expressão de formas variadas e múltiplas de poder, violência $e$ de exacerbação das desigualdades sociais possibilitadas por $e$ praticadas nesses ambientes. Nesse sentido, o que entendemos como tecnopolítica, a politização do desenho tecnológico levando em conta sua perspectiva técnica e infraestrutural, é fundamental. 
Em um segundo momento, os artigos concentraram-se na crítica à não-situacionalidade do trabalho $e$ das práticas no campo das TICs. Recuperando discussões e perspectivas feministas, os artigos dão corpo às múltiplas desigualdades de gênero, classe $e$ raça que se produzem nesses contextos sociais, voltando-se para discussões sobre o (auto)cuidado, a técnica e suas habilidades, $e$ sobre ancestralidade e políticas identitárias como estratégias de existência e resistência.

Graciela Natansohn e Josemira Reis enfocam as convergências e tensões entre a ética hacker e a ética do cuidado a partir da atuação de coletivos hackerfeministas. $\mathrm{O}$ artigo chama a atenção para um panorama do capitalismo de dados marcado pelo enviesamento dos códigos que assumem perspectivas generificadas, racializadas e geopoliticamente localizadas, $e$ resultam em situações de vulnerabilidade e violência nas redes digitas. Diante deste cenário, as autoras evidenciam como coletivos hackerfeministas têm elaborado estratégias de resistência que desafiam esses padrões ao criarem redes de acolhimento $e$ solidariedade, reivindicando a incorporação do autocuidado na tecnociência.

Com um olhar voltado para as intersecções entre gênero $e$ raça, Dulcilei Lima e Taís Oliveira pensam as estratégias de resistência que coletivos negros têm arregimentado a partir da apropriação tecnológica e a constituição de redes de ciberativistas negras. As autoras apresentam a Rede Negras In Tech, criada a partir da correlação dos resultados do PretaLab Report. Este levantamento buscou identificar mulheres negras $e$ indígenas atuantes nas tecnologias, com a análise de redes sociais para mapear conexões entre as iniciativas identificadas no relatório. Tais grupos se articulam em redes online com o propósito de desenvolver espaços de visibilidade para múltiplas pautas sociais $e$ o compartilhamento de saberes.

O artigo Objeçôes Têxteis: Interferência e Ativismo TêxtilDigital costura essa discussão partindo das relações entre

${ }^{1}$ https://www.pretalab.com/ - último acesso em 26/10/2020 
tecelagem, informação e tecnologia digital. As autoras Tania Pérez-Bustos e Laura Juliana Cortes Rico exploram elementos, ações e dinâmicas que perpassam tanto as distintas formas de fazer, desenhar e produzir tecidos, como o desenho e as técnicas de confecção de tecnologias digitais. Alinhavam algumas das relações históricas e contemporâneas que envolvem corpos, técnicas, ideias e materialidades nos processos de "fazer à mão" $e$ de "fazer à máquina". De uma perspectiva feminista, as autoras exploram as "objeções" que emergem das diferentes técnicas $e$ cotidianos entre a engenharia $e$ a tecelagem artesanal.

Na sequência, e fechando as discussões deste dossiê, os três últimos artigos enfatizam as relações entre corpos e tecnologias, demonstrando de que modo tais interações produzem ou desativam normatizações em torno do gênero.

Gabriela Paletta, Marina Nucci e Daniela Manica apresentam e discutem as tecnologias de informação aplicadas à saúde, com enfoque sobre a saúde reprodutiva feminina, crescentemente monitorada por aplicativos de gravidez e do ciclo menstrual. $\mathrm{O}$ artigo traz para o centro do debate questóes relativas à normatividade e controle dos corpos transpostas para uma experiência de vigilância digital e produção massiva de dados sobre saúde e sexualidade.

Débora Allebrandt e Camilla Freitas discutem os agenciamentos de tecnologias de reprodução assistida a partir de grupos e canais em redes sociais digitais que conectam pessoas que estão tentando ter filhos, identificadas como "tentantes". O protagonismo das mulheres nessas interações evidencia a responsabilidade que ainda recai sobre elas na ausência involuntária de filhos. Por outro lado, porém, colabora para a desconstrução de tabus em torno da infertilidade, deslocando uma discussão até então circunscrita na esfera íntima para o espaço "público" das redes digitais.

Ao abordar as tecnologias que se fazem corpo, com o trânsito de técnicas, substâncias e a produção de subjetividades minoritárias, Érica Souza aborda a constituição de corpos de homens trans. Se corpos e substâncias, como os hormônios, são 
performados como sistemas de informação, em geral visando o controle e a normatização, os processos de transição de gênero podem ser pensados como procedimentos técnicos que "hackeiam" e tensionam o binarismo ancorado na gramática corporal.

Dessa forma, fechamos o dossiê com uma discussão que toma criticamente a dimensão técnica da construção de corpo $e$ gênero, e de uma perspectiva que leva em conta seus desdobramentos na saúde, biomedicina e direito, passando pelos embates em torno da desmedicalização e despatologização, $e$ pelos ativismos pelos direitos da população trans.

Esperamos, com os trabalhos reunidos neste dossiê, atualizar e recuperar discussões que refletem sobre o exercício da autonomia e da liberdade no contexto colonizado pelas grandes corporações do capitalismo de vigilância nas redes informacionais contemporâneas. Pretendemos, assim, contribuir de uma perspectiva feminista para pensar como habitar corpos e redes que tenham múltiplas possibilidades de futuro.

\section{Daniela Camila de Araújo** Daniela Tonelli Manica*** Marta Mourão Kanashiro****}

\section{Referências bibliográficas}

DESPRET, Vinciane; STENGERS, Isabelle. Les faiseuses d'histoires: que font les femmes à la pensée? Pais: La Découverte, 2011.

\footnotetext{
** Integrante da Organização Feminista MariaLab, Campinas, SP, Brasil. daniela.camila.araujo@gmail.com / https://orcid.org/0000-0003-1187-0223

*** Pesquisadora do Laboratório de Estudos Avançados em Jornalismo / Núcleo de Desenvolvimento da Criatividade, Unicamp, Campinas, SP, Brasil. dtmanica@unicamp.br/https://orcid.org/0000-0001-8014-9996

**** Pesquisadora do Laboratório de Jornalismo (Labjor) da Universidade Estadual de Campinas (Unicamp) e membro fundadora da Rede Lavits (Rede Latinoamericana de Estudos sobre Vigilância, Tecnologia e Sociedade), Campinas, SP, Brasil.mmk@riseup.net / https://orcid.org/0000-0002-1337-3186
} 
HARAWAY, Donna. Manifesto Ciborgue: ciência, tecnologia e feminismo-socialista no final do século XX. In: TADEU, T. (Org.) Antropologia do ciborgue: as vertigens do pós-humano. Belo Horizonte: Autêntica, p. 33-118. 2009. 